\title{
Behavioural responses of the planktonic stages of the American lobster Homarus americanus to thermal gradients, and ecological implications*
}

\author{
Bernard Boudreau $^{1}$, Yvan Simard $^{2}$, Edwin Bourget ${ }^{1}$ \\ ' GIROQ, Département de Biologie, Université Laval, Ste-Foy, Québec, Canada G1K 7P4 \\ ${ }^{2}$ Ministère des Pêches et des Océans, Institut Maurice-Lamontagne, 850 route de la Mer, C.P. 1000, Mont-Joli, Québec, \\ Canada G5H 3 Z4
}

\begin{abstract}
The behavioural responses of each planktonic stage (I to IV) of American lobster Homarus americanus to a thermal gradient were studied during complete day/night cycles using an experimental approach. The thermocline markedly influenced the vertical position of larvae of all stages, limiting their distribution to the upper part of the water column. In both absence or presence of a thermocline, older individuals (stages III \& IV) were observed deeper in the water column than younger individuals (stages I \& II). The vertical distribution of larvae was unaffected by the day/night regime. The ecological significance of this temperature-driven behaviour of the larvae relative to the recruitment dynamics of the adult stocks is discussed. We hypothesize that factors causing a breakdown in the thermocline should decrease recruitment to the adult population. The validity of this hypothesis was explored for the lobster stock of Iles-de-la-Madeleine (Gulf of St. Lawrence, Québec). Significant negative correlations obtained between the frequency of strong winds $\left(>30 \mathrm{~km} \mathrm{~h}^{-1}\right)$ during dispersal and settlement periods, and subsequent lobster landings (with an $8 \mathrm{yr}$ lag) in this region over a $15 \mathrm{yr}$ interval support the hypothesis.
\end{abstract}

\section{INTRODUCTION}

Dispersal and ultimately survival of meroplanktonic larvae are strongly influenced by their ability to control their vertical position in the water column (Shanks 1986). Meroplanktonic larvae of most benthic species are known to be heterogeneously distributed with depth, both in estuaries and coastal waters (for general reviews see Banse 1964, Young \& Chia 1987). Throughout the period of larval dispersion, the vertical distribution of larvae involves behavioural responses to exogenous factors as well as endogenous changes in behaviour, anatomy, and physiology (Forward 1976, 1988, Sulkin 1984, Power 1989). Although hydrodynamic conditions have some influence on larval vertical distribution, the primary depth regulatory mechanisms are probably under behavioural control, involving alternate periods of swimming and sinking in response

\footnotetext{
- Contribution to the programmes of GIROQ (Groupe Interuniversitaire de Recherches Océanographiques du Québec) and of the Maurice-Lamontagne Institute
}

to various environmental stimuli (e.g. light, pressure, and gravity; Sulkin 1984, Forward 1988).

In continental shelf ecosystems such as estuarine and coastal environments, hydrographic conditions often lead to temperature and salinity stratification of the water column which could alter the basic pattern of vertial movements of the larvae (Young \& Chia 1987. Forward 1988). The effect of salinity and temperature gradients on the vertical distribution of zooplankton has been reviewed by several authors (Cushing 1951, Banse 1964, Young \& Chia 1987). It appears in general that water stratification is not an absolute physical barrier, but near the discontinuity the larvae often change their behaviour and therefore their distribution pattern. Indeed, the literature on holoplankton shows that the vertical distributions of some species are confined above, near or below the thermocline, but other species are indifferent to temperature stratification (Hansen 1951, Angel 1968, Paffenhöfer 1983, Fragopoulu \& Lykakis 1990). Field studies on the vertical distribution of meroplanktonic species in relation to the thermocline also show a wide range of results. Some 
species are strongly influenced by the thermocline (Oshurkov et al. 1982, Tremblay \& Sinclair 1990) while others are apparently indifferent to it (Turner \& Dagg 1983). At smaller spatial scales, the aggregations of zooplankton observed in the field can occur within regions of sharp temperature gradients associated with thermal microstructure (Boyd 1973). In the laboratory, recent studies on the estuarine crabs Callinectes sapidus and Eurypanopeus depressus, and the deep sea red crab Geryon quinquedens, have shown that sharp thermal gradients have no inhibitory effect on upward movements of the hatching stage (Kelly et al. 1982, Sulkin et al. 1983, McConnaughey \& Sulkin 1984). Unfortunately, there is no information about the behavioural responses of these crab larvae in relation to the thermocline after they have reached their upper limit in the water column. Moreover, the studies carried out to date have been concentrated on decapod species living in estuaries, where gradients are extreme. Little is known about species inhabiting coastal environments, such as the American lobster Homarus americanus.

Several aspects of the larval ecology of the American lobster remain obscure, reducing our ability to effectively manage the fishery (Sinclair et al. 1988). One of these is the dynamic interaction between larval behaviour and environmental factors during dispersal and settlement (Boudreau et al. 1990), and how this interaction affects recruitment (Phillips \& Sastry 1980, Ennis 1986). Until recently, the larvae of the American lobster were believed to be neustonic animals, both from inshore and offshore studies (Scarratt 1964, 1973, Stasko \& Gordon 1983\}. However, studies carried out on Browns Bank (southwest of Nova Scotia, Canada) by Harding et al. (1987) have shown evidence that planktonic stages of the American lobster may be found over the upper $30 \mathrm{~m}$ of the water column. In particular, stage I larvae seem to undergo significant vertical migrations, with a high proportion of the population being located above $10 \mathrm{~m}$ during nighttime and down to $30 \mathrm{~m}$ during daytime (Harding et al. 1987). Caddy (1979) postulated the existence of vertical migrations out of the mixed layer in the lobster larvae of Northumberland Strait (between Prince Edward Island and Nova Scotia), as a mechanism for maintaining horizontal position despite a presumed Ekman stratified flow (see Myers \& Drinkwater 1989). It must be stressed here, however, that the ranges of the distribution observed on Browns Bank by Harding et al. (1987) for stages I, II, and III were all confined to the upper mixed layer above the thermocline.

Although the vertical distribution of lobster larvae seems to be mainly controlled by their orientation responses to light (Hadley 1908) and their kinesis responses to hydrostatic pressure changes (Ennis
1975), other hydrographic components may be involved in their vertical movements. According to Scarratt \& Raines (1967), hatching larvae are not influenced by a salinity gradient of 31.9 to $26.7 \%$ but show a strong avoidance reaction to low salinities $(<22 \%)$. However, very low salinities are more characteristic of estuarine environments where lobsters are absent. A more general physical gradient in the lobster ecosystems is temperature. To date, no attempts have been made to examine the potential effect of the thermocline as a factor limiting vertical movements of lobster larvae

The present study was undertaken to test the hypothesis that the behavioural responses of the planktonic stages of the American lobster are modified by the presence of a sharp thermal gradient in the water column. Our approach was to compare behaviour of larvae from stages I to IV, through their relative distribution in 2 different water columns in the laboratory one strongly stratified, the other, a control, totally unstratified. The results are discussed in the context of larval dispersion and survival in the field.

\section{MATERIALS AND METHODS}

Larval rearing conditions. Nine ovigerous female lobsters Homarus americanus (with eggs having eye indices ranging from 150 to $477 \mu m_{i}$ Perkins 1972) were obtained from Iles-de-la-Madeleine (Gulf of St. Lawrence, Québec) in June 1989 and held individually in 901 open system containers. The tanks were maintained at constant temperatures, ranging from 9.5 to $22^{\circ} \mathrm{C}$, to spread hatching time over a 3 mo period.

The newly hatched larvae were collected in catch baskets at the outlet of the female's tank and gently transferred to a semi-closed system of six 601 planktonkreisels (Hughes et al. 1974). Water temperature in these tanks was kept constant (from $12^{\circ} \mathrm{C}$ for tank \#1 to $22^{\circ} \mathrm{C}$ for tank \#6), using immersion heating rods controlled by thermoregulators (precision of $\pm 0.5^{\circ} \mathrm{C}$ ), to provide a continuous larval supply during experiments. Siblings of the same age $(\Delta t \leq 24 \mathrm{~h})$ were reared together. Larvae were fed once daily, to slight excess, with newly hatched (12 to $24 \mathrm{~h}$ ) Artemia franciscana nauplii (Argent Chemical Laboratories). Both ovigerous females and larvae were kept under artificial light on a 12L: 12D cycle.

Experimental equipment. The equipment for generating and maintaining precise, stable thermoclines $\left(\Delta t \approx 1^{\circ} \mathrm{C} \mathrm{cm}^{-1}\right)$ was designed as follows. The base of the experimental column (inside dimensions $19 \times 10 \times 190 \mathrm{~cm}$ water depth), filled with water at room temperature $\left(20 \pm 2^{\circ} \mathrm{C}\right)$, was set in a circular cooling tank $(50 \mathrm{~cm}$ diameter $\times 50 \mathrm{~cm}$ height) with 


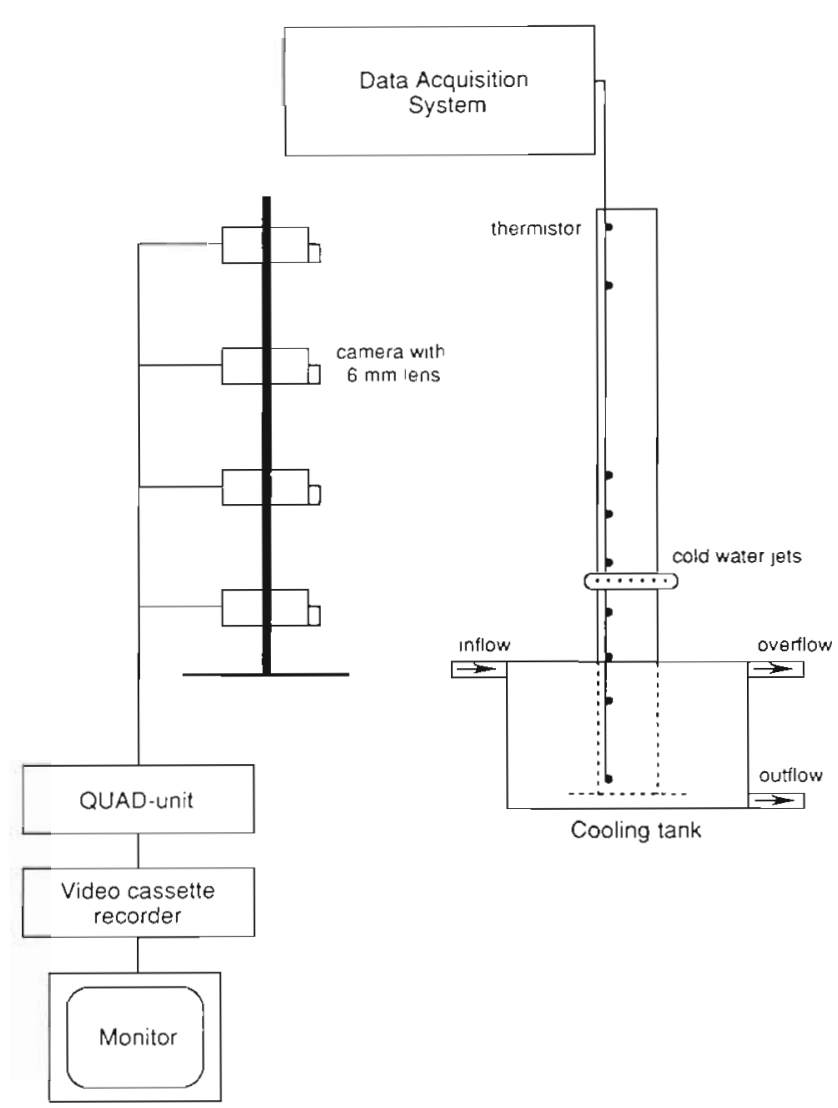

Fig. 1 Diagram of the experimental tank and the video monitoring system used to test larval responses to the thermocline. The control column (not shown) was filmed simultaneously

circulating water at constant $8.5^{\circ} \mathrm{C}$ (Fig. 1). Temperatures generated were similar to those encountered by larvae in the field (i.e. 17 to $20^{\circ} \mathrm{C}$ at the surface and 8 to $10^{\circ} \mathrm{C}$ near the bottom; Gregory et al. 1990 , Petrie 1990). In order to vary the position of the thermocline, a mobile collar of cold water jets was placed around the outside of the column (Fig. 1). Nine thermal sensors $\left( \pm 0.3^{\circ} \mathrm{C}\right.$; Fenwal Electronics) were installed at different depths to determine the vertical temperature profile. Data were recorded at 5 min intervals with an Apple IIe computer via a 12-bit analog/digital interface (Analog Devices, model 17I). The sharp thermoclines generated were stable and could be maintained as long as wanted. Vertical distributions of stages $I I I$ and IV lobster larvae were monitored with a closed circuit video time-lapse system (4 Model CD-20 cameras, Color Quad Unit WJ-450, VHS/VCR AG-6010, and a monitor WV-5470 by Panasonic; Fig. 1). Hourly distribution of first and second stage larvae were determined by direct observation since the individuals were too small for video taping. Illumination during light (L) phase was provided by 2 timer-controlled daylight type fluorescent lights. To minimize light disturbance dur- ing the dark (D) phase, 2 red fluorescent lights (Silvania Model R40) emitting wavelengths between 600 and $700 \mathrm{~nm}$ were used. These wavelengths are known to be poorly absorbed by lobster visual pigments (Bruno et al. 1977). Fluorescent lights were located above the water columns.

Experimental design. Experiments were designed to determine whether: (1) the vertical distribution of larvae varied among the different stages; (2) it varied during periods of light and dark; and (3) the thermocline could restrict the vertical distribution of the larvae.

Two columns, side by side, were tested (and filmed) simultaneously: an experimental column with a thermocline and a control column without one. The control column was similar to the experimental one except for the thermistors, which were dummy. Temperatures in the control column were recorded at the start and end of experiments using a thermometer. Because light is an important depth regulatory factor for lobster larvae (Hadley 1908), the light profile in the 2 columns was established using a Biospherical quantum meter. The light gradients in the 2 tanks were almost identical (Fig. 2).

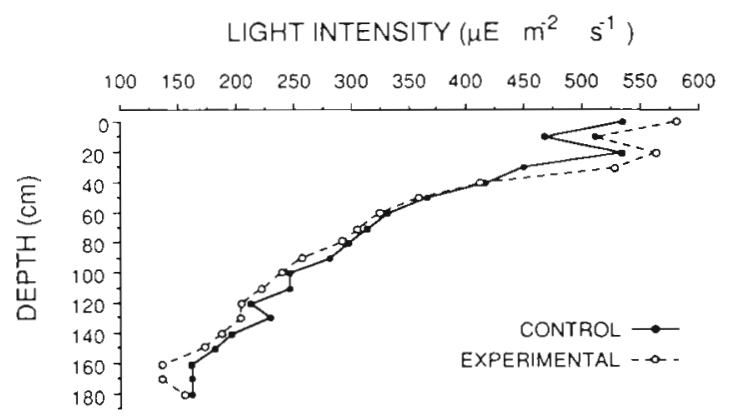

Fig. 2. Light intensity during the day in the control and experimental water columns in relation to depth

The overall design was the same for all experiments. At the start of the experiments, a fixed number of lightand temperature-adapted larvae (30 for the experiments with stage I individuals; 20 for stage II; 15 for stage III and 10 for stage IV) were released simultaneously at the surface of both the control and the experimental tanks. For experiments with stage IV larvae, only recently moulted ( 2 to $3 \mathrm{~d}$ ) individuals were used because older individuals became bottom seeking. Two thermocline positions, $1.0 \mathrm{~m}$ and $1.4 \mathrm{~m}$ deep, were tested with stage I larvae. Other planktonic stages were exposed to a $1.4 \mathrm{~m}$ deep thermocline only. All experiments were carried out for $24 \mathrm{~h}$ periods in a closed seawater system with a 12L:12D cycle. Larval distribution, based on counts of all larvae per $10 \mathrm{~cm}$ depth sections, was determined every hour, by choos- 
ing randomly one of the twelve 5 min intervals of film. Larvae were only used once. Each experiment was replicated 3 times with larvae from different females. Larvae were not fed during the experiments.

Data analysis. To test whether the vertical distributions of lobster larvae changed with developmental stage or the day/night light cycle, the following method was used. Since the entire water column was sampled, the usual approach of the Kolmogorov-Smirnov 2-sample test could be used to test the null hypothesis that the 2 observed distributions (control vs experimental) come from the same underlying distribution (Venrick 1986). However, the parametric testing of the Kolmogorov-Smirnov's statistic $D$ involves the assumptions of random sampling and independence of observations. Both of these assumptions failed under the current circumstances. Consequently a non-parametric randomization procedure ('bootstrap' approach) was used. First, the null distribution of the KolomogorovSmirnov's statistic (i.e. its distribution under the null hypothesis) was computed from 5000 estimates of the statistics $\left(D_{\alpha}\right)$ generated from random trials of the observed larval distributions. The resulting frequency distribution of $D_{a}$ represents the exact null distribution of $D_{a}$ for these data. Secondly, the actual value of the statistic $D_{c}$ was computed from the 2 observed distributions. Finally, $D_{c}$ was tested against the frequency distribution of $D_{a}$ to determine the probability of observing a $D_{a}$ greater or equal to $D_{c}$ by chance alone. A similar procedure was used to test the Pearson correlation coefficients ( $r$ ) computed between the vertical distributions of the larvae and temperature profiles.

The influence of the thermocline on larval distribution was tested using Cochran's corrected chi-square statistics for the $2 \times 2$ contingency table. The level of the thermocline in the experimental column was used as a reference level to test the null hypothesis that larval frequencies above and below this reference point were independent of treatment. For this test, the data of all replications were pooled, since these replications were homogeneous (heterogeneity chi-square analysis; $\chi^{2} \leq 1.10, \mathrm{df}=2, \mathrm{p}>0.50 ;$ Zar 1984)

To assess if the differences between the distribution of larvae from the experimental and control columns could be attributed to temperature differences, Mantel tests were used (Mantel 1967, Legendre \& Fortin 1989, Simard \& Savard 1990). This method allows comparison between 2 distance matrices ( $X$ and $Y$ ) using their sum of products element by element as statistics. Here the 2 matrices were the dissimilarities in (1) larval distributions and (2) temperatures between the experimental and control water columns. The dissimilarity index used was the Euclidean distance index $D_{E}$ (Legendre \& Legendre 1984). The dissimilarity between samples $x_{1}$ and $x_{2}$ is given by:

$$
D_{\mathrm{E}}\left(x_{1}, x_{2}\right)=\sqrt{\sum_{k=1}^{15}\left(y_{k 1}-y_{k 2}\right)^{2}}
$$

where $y_{k}$ is the temperature or the larval distribution data in the experimental (1) and control (2) columns. The Mantel statistic, $Z_{1}$ was then computed to compare the 2 matrices:

$$
z=\sum_{i} \sum_{j} X_{i_{j}} Y_{i_{j}}(i \neq j)
$$

where $i$ and $j$ are the non-redundant lines and columns of the matrices (diagonal excluded)

The null hypothesis of the independence of the elements of the 2 matrices was tested by comparing the actual value of $z$ to the reference distribution under $H_{\circ}$, obtained from 250 random permutations of the rows and columns of one matrix.

\section{RESULTS}

\section{Temperature effects on larval distribution}

The thermocline strongly influenced the vertical distribution of larvae (Fig. 3). In the absence of thermocline (control column), significant negative correlations were observed for stages I and III and to a lesser degree, for stage II larvae, indicating that these stages were concentrated in the lower part of the column. In contrast, when the column was stratified (experimental column), significant positive correlations were observed for stages I and II, indicating that larval distribution was limited in the upper warm section of the tank. The distribution of the fourth larval stage showed no correlation with temperature both in control and experimental column (Table 1).

The distribution within columns for each experimental situation was examined more closely using contingency tables. Fig. 3 shows that the abundance of larvae in the cold $50 \mathrm{~cm}$ below the thermocline was significantly reduced compared to the corresponding controlied situations (corrected $\chi^{2} \geq 165.3, \mathrm{df}=1$, $\mathrm{p}<0.0001)$. The comparison of larval distributions between the control and experimental columns also suggests that the critical temperature affecting behaviour is between 10 and $15^{\circ} \mathrm{C}$ (Fig. 3).

Mantel tests were used to determine if the discrepancies between the larval distribution patterns observed in the control and experimental columns were attributable to differences in temperature. The distance matrices of larval distributions and temperatures were significantly correlated (Table 2), indicating that the observed differences in the larval distributions were associated with temperature variations. 

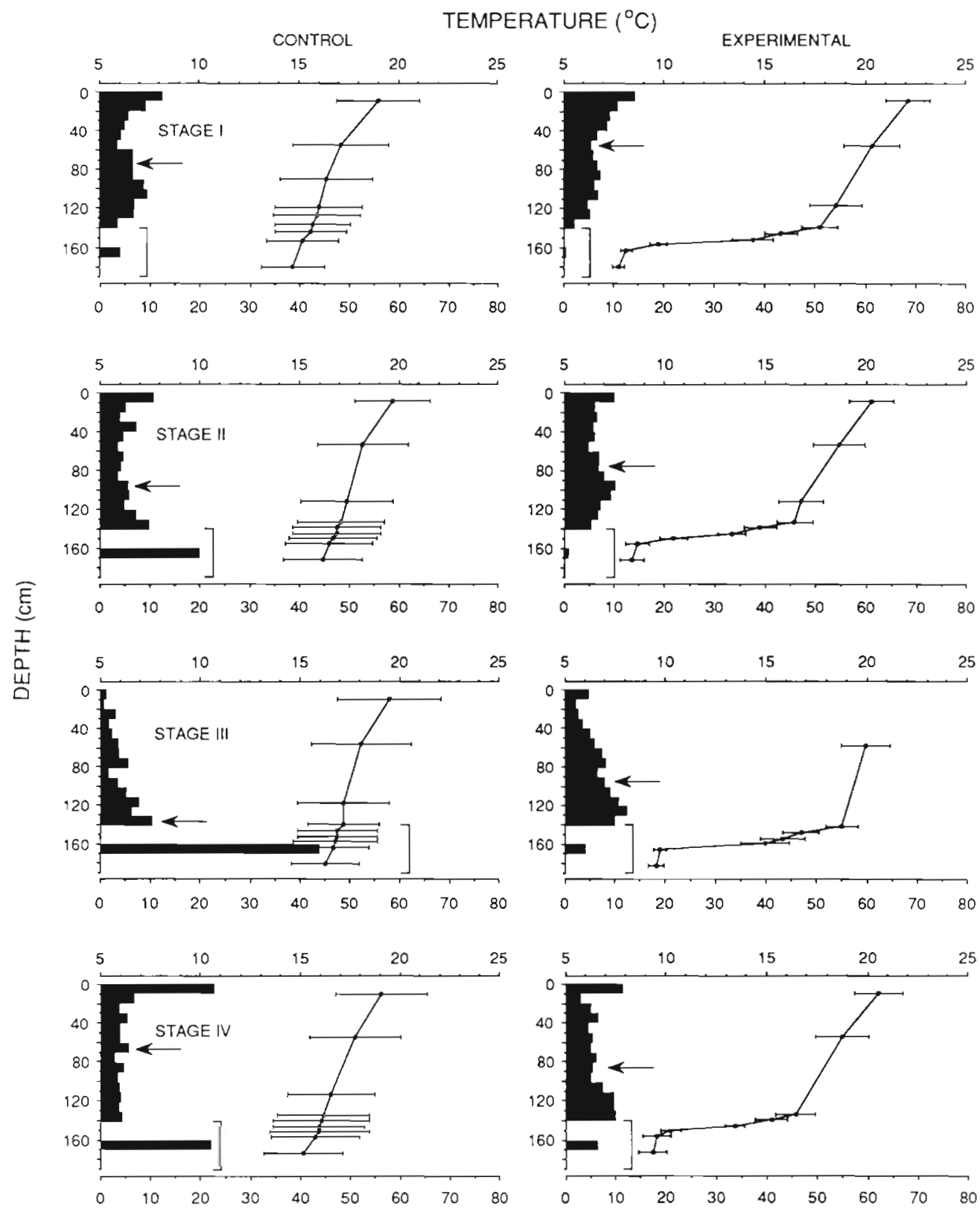

FREQUENCY (\%)

Fig. 3 Homarus americanus. Daily vertical distribution of the 4 lobster planktonic stages (bar graph) in relation to temperature (line graph; $\bar{x} \pm \mathrm{SD}$ ). Frequencies represent the total number of larvae counted at each hour of experiment $(\mathrm{n}=3$ replicates). Median depth of larval distribution is indicated by an arrow. In all cases, the abundance of larvae in the bottom $50 \mathrm{~cm}$ is considerably reduced by the presence of the thermocline (corrected chi-square test, $\chi^{2} \geq 165.3, p<0.0001$ )

The importance of the thermal gradient in limiting the larval distribution was confirmed in the experiment where the thermocline was raised by $0.4 \mathrm{~m}$ in the column (Fig, 4). The median depth of the larval distribution was significantly higher in the water column when the thermocline was set at $1.0 \mathrm{~m}$ compared to $1.4 \mathrm{~m}$ depth (median test $\chi^{2}=182.36, \mathrm{df}=1$, $\mathrm{p}<0.0001 ;$ Zar 1984).

\section{Ontogenetic variation}

In absence of a thermocline, there was a tendency for older larvae (stages II, III and IV) to occupy lower portions of the column (see median depths on Fig. 3). A similar effect, though less pronounced, was observed in the presence of the thermocline: a larger proportion of individuals managed to cross the thermocline as they 
Table 1. Homarus americanus. Pearson correlation coefficients ( $\mathrm{r}$ ) between the relative abundance of lobster larvae per $10 \mathrm{~cm}$ depth intervals and corresponding mean temperature. Coefficients were tested on a null distribution obtained from randomization procedure $(\mathrm{n}=5000$ random permutations for each sample)

\begin{tabular}{|c|c|c|c|c|}
\hline \multirow[b]{2}{*}{ Stage } & \multicolumn{2}{|c|}{ Control } & \multicolumn{2}{|c|}{ Experimental } \\
\hline & $\mathrm{r}$ & $\mathrm{p}$ & $r$ & $p$ \\
\hline I & -0.42 & $0.05^{\circ}$ & 0.78 & $0.00 \cdots$ \\
\hline II & -0.37 & 0.09 & 0.62 & $0.03 \cdots$ \\
\hline III & -0.58 & $0.00^{\cdots}$ & 0.03 & 0.44 \\
\hline IV & 0.06 & 0.37 & -0.13 & 0.32 \\
\hline \multicolumn{5}{|c|}{$\cdot p=0.05 ; \cdots p<0.05 ; \cdots p<0.001$} \\
\hline
\end{tabular}

Table 2. Homarus americanus. Mantel statistic ( $z$ ) between the distance matrix of the relative larval abundances (experimental-control) and the distance matrix of the temperatures (experimental-control) for each lobster planktonic stage

\begin{tabular}{|ccc|}
\hline Stage & $z$ & $p$ \\
\hline I & 2314.3 & $0.05 \cdot$ \\
II & 2766.7 & $0.00 \cdots$ \\
III & 6396.6 & $0.00 \cdots$ \\
IV & 3390.1 & $0.01 \cdots$ \\
$p=0.05 ; \cdots p=0.01 ; \cdots p<0.001$ & \\
\hline
\end{tabular}

grew older (Fig. 3). In the controls, the first stage presented a significantly different distribution from the second and third ones (Table 3). This discrepancy can be ascribed to the greater proportion of larvae near the bottom in the experiments with the second and third stages. In experimental conditions, vertical distributions of both stages I and II were significantly different from older stages (III and IV; Table 3). This is probably attributable to a general tendency to accumulate in the

Table 3. Homarus americanus. Ontogenetic variation in the vertical distributions among different planktonic stages both in the control and experimental columns. Comparisons of larval vertical distributions were made using KolmogorovSmirnov statistics $\left(D_{c}\right)$ tested by a non-parametric randomization procedure $(n=5000$ random permutations of each sample)

\begin{tabular}{|c|c|c|c|c|}
\hline \multirow{2}{*}{$\begin{array}{c}\text { Stages } \\
\text { compared }\end{array}$} & \multicolumn{2}{|c|}{ Control } & \multicolumn{2}{|c|}{ Experimental } \\
\hline & $D_{c}$ & $\mathrm{p}$ & $D_{c}$ & $\mathrm{p}$ \\
\hline I vs II & 0.22 & $0.02^{\circ}$ & 0.16 & 0.10 \\
\hline I vS III & 0.47 & $0.00^{\cdots}$ & 0.31 & $0.00^{\cdots}$ \\
\hline I vs IV & 0.19 & 0.41 & 0.24 & $0.00^{*}$ \\
\hline II vs III & 0.27 & 0.67 & 0.17 & $0.04^{\circ}$ \\
\hline II vs IV & 0.14 & 0.87 & 0.15 & $0.03^{\circ}$ \\
\hline III vs IV & 0.36 & 0.48 & 0.13 & 0.24 \\
\hline
\end{tabular}

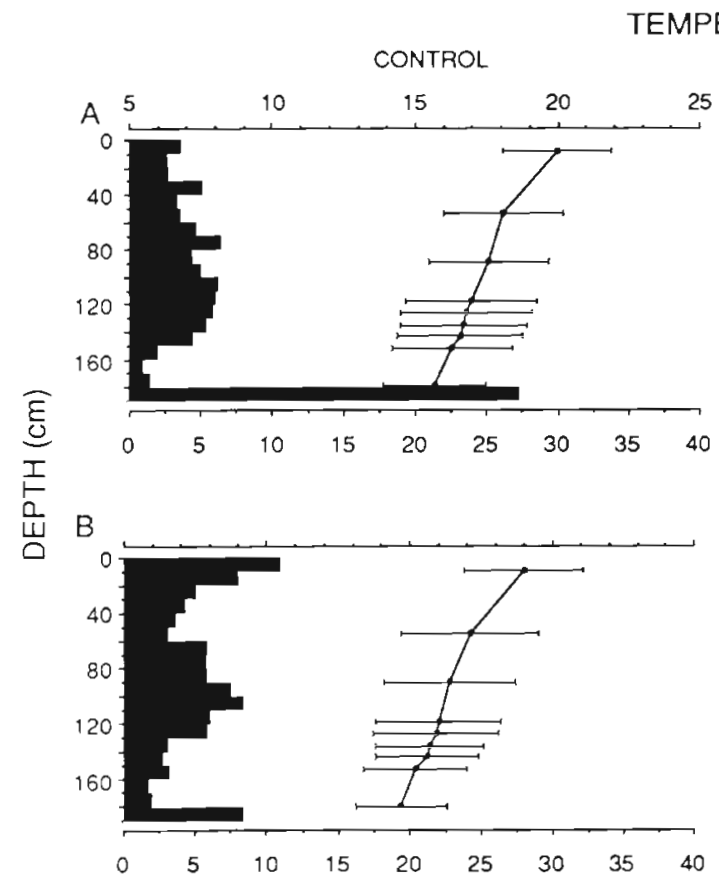

EXPERIMENTAL
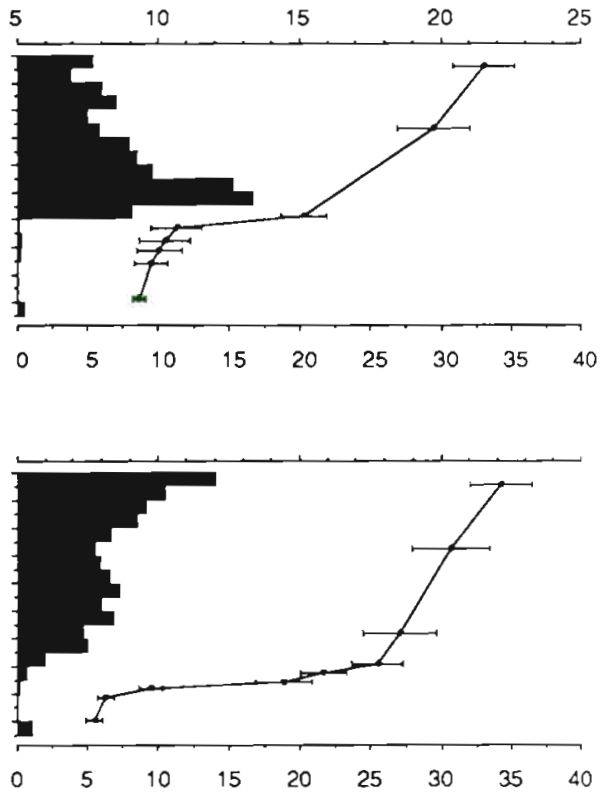

STAGE I LARVAE (\%)

Fig. 4. Homarus americanus. Spatial distribution of stage I lobster larvae (bar graph) in relation to temperature (line graph; $\bar{x} \pm$ SD) when the thermocline was at (A) $1.0 \mathrm{~m}$ and (B) $1.4 \mathrm{~m}$ depth. Frequency data were based on the total number of larvae counted during each hour of experiment ( $\mathrm{n}=3$ replicates). The larvae were significantly higher in the expenmental water column when the thermocline rose by $0.4 \mathrm{~m}$ (median test, $x^{2}=182.36, \mathrm{p}<0.0001$ ) 
lower part of the water column as the larvae grew older (Fig. 3). No significant difference was observed among other stages both in control and experimental treatments (Table 3).

\section{Nyctemeral variations}

The influence of the day/night cycle of illumination was examined for each planktonic stage in both control and experimental conditions (Fig. 5). The results indicate no significant differences between the light and dark periods, suggesting no diel variation in the vertical distribution of the larvae both in presence and in absence of a thermocline (Kolmogorov-Smirnov 2 sample randomized test, $D_{\mathrm{c}} \leq 0.17, \mathrm{p}>0.25$ ) (Fig. 5).

\section{Behavioural responses to the thermocline}

The results clearly indicate that the depth-regulatory behaviour of lobster larvae is strongly influenced by thermal gradients. There was a near total confinement of the larvae above the well-established stable thermoclines generated in the experimental column. Recent field observations show that lobster larvae are restricted to the upper $30 \mathrm{~m}$ of the water column, corresponding to the region above the thermal gradient (Harding et al. 1987). These authors found only 1 lobster larva below the thermocline. Thus their results suggest that our observations have some similarity with those encountered in the field. Studies on spiny lobsters (Palinuridae), however, report contrasting reactions of larvae to temperature discontinuities. Rimmer

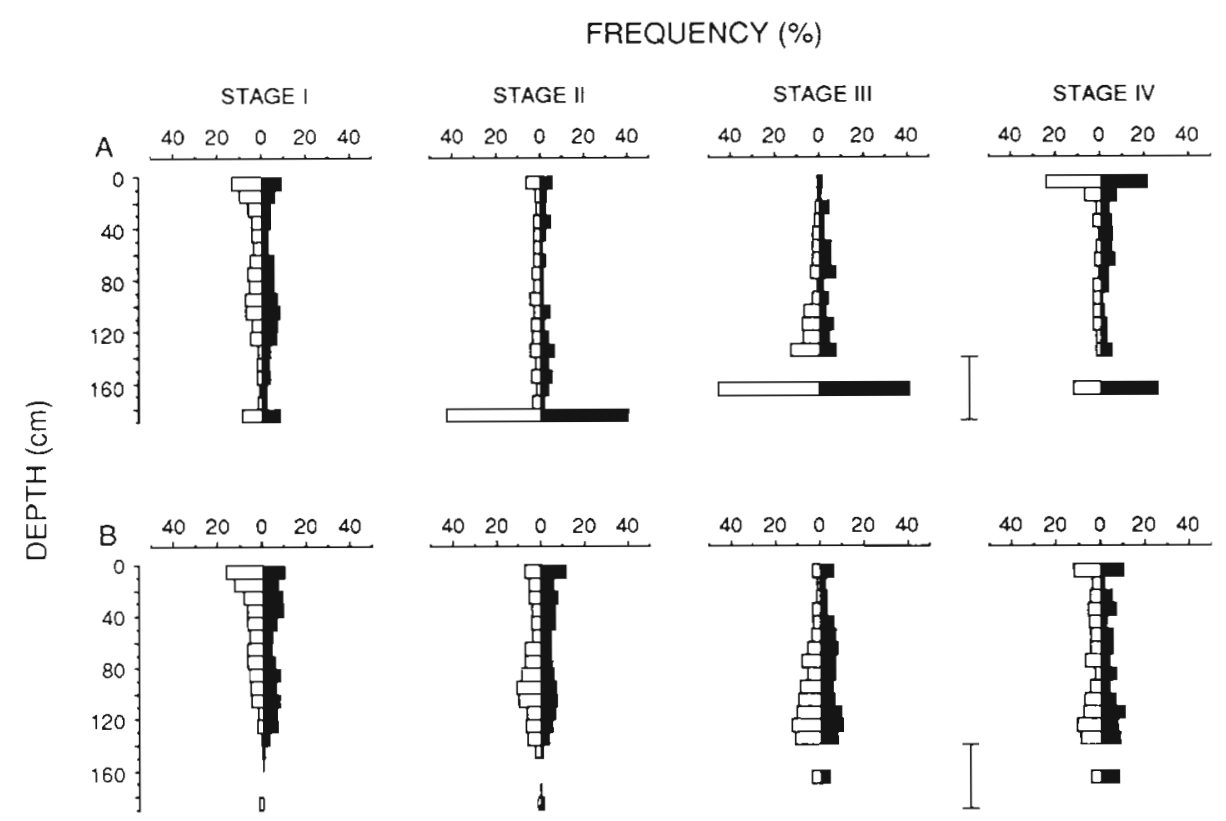

Fig. 5. Homarus americanus. Vertical distribution of lobster larvae in relation to light (open bars) and dark (black bars) periods in (A) control and (B) experimental column. Frequency data were based on the total number of larvae counted during each hour of experiment ( $\mathrm{n}=3$ replicates). Larval distributions were not significantly different between the light and dark periods (Kolmogorov-Smirnov 2-sample randomized test, $D_{c} \leq 0.17, \mathrm{p}>0.25$ )

\section{DISCUSSION}

Survival of planktonic larvae is associated with their capacity to control their vertical position in the water column via behavioural adaptations. Recent reviews indicate that many meroplanktonic larvae respond to exogenous stimuli such as light and gravity by directional movements, but very few experimental studies have examined how physical discontinuities could alter the behaviour of larvae (Sulkin 1984, Young \& Chia 1987, Forward 1988). Our primary objective in the present study was to determine the effect of a sharp thermal gradient on larval behaviour of the American lobster Homarus americanus.
\& Phillips (1979), working on western rock lobster Panulirus cygnus, found no limiting effect of the thermocline on vertical migrations. In contrast, Austin (1972) reported that the larvae of Panulirus argus were restricted in their vertical movement by the presence of a sharp shallow thermal gradient. In recent studies on behavioural responses of 2 estuarine crab larvae to rates of change in temperature, Forward (1990) observed that both species swam upward following a temperature decrease. Present results suggest that American lobster larvae respond in a similar way. This behaviour may be attributed either to a temperature alteration of the normal response of the larvae to other exogenous stimuli (e.g. light, pressure, gravity) or to a 
direct negative reaction to the temperature decrease. In other words, during their vertical movements, larvae may perceive the thermal gradient as an orientation cue and then move in relation to it, like benthic animals orienting toward a food source following a chemical gradient (see McLeese 1973). If this interpretation is correct, larvae should also react negatively to cold horizontal thermal gradients such as those encountered in frontal zones. This hypothesis has yet to be tested.

\section{Ontogenetic variation}

The limiting effect of the thermocline was less pronounced for older (stages III and IV) than for younger larvae. Old, large individuals tended to sink and accumulate near the bottom in controls, or immediately above the thermocline in the experimental columns. However, with age, an increasing fraction (from $0.3 \%$ in stage I to $6.3 \%$ in stage IV) of individuals crossed the gradient. Field observations (Harding et al. 1987) suggest that very few individuals cross the thermocline, and that old individuals are observed closer to the surface than to the thermocline. This difference with our results could be explained in the following 2 ways. Firstly, in the field, it is possible that, having crossed the thermocline, larvae sink rapidly to the deeper depths according to a negative thermokinesis (Sulkin 1984), and therefore could be underrepresented in samples. Secondly, it is also possible that the artificial thermocline, which was no more than $17 \mathrm{~cm}$ thick in the experimental column, could be more easily permeated than the natural thermocline, which is meters thick in the ocean. In this respect, it could be argued that the size of the experimental system $(19 \times 10 \mathrm{~cm})$ may also have limited the horizontal swimming capabilities of the larvae, hence limiting their capacity to maintain themselves in the upper part of the water column. However, direct observations and video recordings of all experiments do not support this hypothesis; rapid vertical movements in both directions were observed during experiments

\section{Diel variation}

Light, pressure and gravity are the main environmental factors currently invoked as depth regulators of meroplankton (Sulkin 1984, Young \& Chia 1987, Forward 1988). Lobster larvae, in particular, are known to react to light (Hadley 1908, Ennis 1975) and pressure (Ennis 1975). In our experiments, all influences other than thermal gradients were alike in both columns, experimental and control. The fact that no changes in distribution of laboratory-reared larvae were observed between light and dark conditions suggests that the apparent diel movements of the larvae observed in nature (Harding et al. 1987) are controlled by other extrinsic factors (e.g. physical instabilities in the water column, food stratification, predators) but larval reactions to other components of the light in the field (e.g. its angular distribution) remain possible. The absence of light effects on larvae in our experimetns, as well as the weak influence of the illumination regime observed by Ennis (1975) contradict the report of Hadley (1908) that the larvae are generally strongly photopositive until late stage IV. In this context, Forward $(1976,1988)$ points out that the phototactic pattern observed in many invertebrate larvae may be reversed with changes in light intensity. Unfortunately, the experimental light conditions were not specified in Hadley's work. Larval reaction to illumination during development is obviously complex, and further work needs to be carried out to clarify the influence of light under conditions nearing natural illumination.

\section{Implications for natural situations}

Advantages and drawbacks for planktotrophic larvae to remaining in the upper mixed layer have been discussed by several authors (Oshurkov et al. 1982, Paffenhöfer 1983, Harding et al. 1987, Pillar et al. 1989). In short, by remaining in the upper mixed layer, larval growth is maximized through higher temperatures and abundance of food, but the larvae may be exposed to higher predation rates. Laboratory studies have demonstrated the strong relationship between temperature and lobster larval survival and growth (Templeman 1936, MacKenzie 1988). For instance, Mackenzie (1988) found that stages III and IV suffered significantly higher mortality when reared at $10^{\circ} \mathrm{C}(>74 \%)$ compared with those cultured at higher temperature $(<25 \%)$, pointing to a direct benefit for larvae to avoid the cold deeper depths. Influence of temperature on survival during early life history stages was also suggested from field studies (Dow 1969, Flowers \& Saila 1972, Caddy 1979, Fogarty 1988). In particular, Fogarty (1988) observed a significant positive correlation. between the surface temperature and the annual catch records with a delay of 6 yr in Maine, USA.

There are other advantages and disadvantages for the larvae to maintaining themselves above the thermocline. Firstly, by limiting their vertical dispersion to the upper mixed layer, larvae could favour their onshore transport to the inshore nursery grounds, where conditions are favorable for post-larval and juvenile survival and growth. Such a case of horizontal transport of larvae toward the coast by surface currents was observed for larval populations of the Gulf of 
Maine and southwestern Nova Scotia (Harding \& Trites 1988). Alternatively, offshore wind-driven currents could carry the larvae out of the coastal waters reducing their chances of survival (Myers \& Drinkwater 1989). Hence, if lobster larval reaction to the thermocline is an adaptation to favour their horizontal transport toward the nursery areas, we expect that different larval populations under different current conditions would respond in different ways to the thermocline. Another possible advantage for competent larvae (midstage IV; Scarratt 1973) to remaining above the thermocline is that by doing so they would minimize the energy expended migrating up and down in search of adequate substrata for settlement, as hypothesized by Scarratt (1973) and Cobb et al. (1983). It is only when the larvae are close to shore that they would either passively or actively be capable of searching for adequate microhabitats, but at much reduced energy costs. However, the present study has focused exclusively on the dispersal phase of lobster and the reactions of competent larvae to thermal gradients remain to be tested.

If this larval strategy of remaining above the thermocline during development is important to ensure adequate growth, feeding and ultimately recruitment for a given cohort, it follows that any factor disrupting the thermal gradient would have a negative effect on larval survival and eventually on recruitment to adult stocks. Hence, we predict that in northern environments such as the Gulf of St. Lawrence, where the upper water column is thermally stratified in summer (Lauzier 1952), recruitment will be reduced, when gale force winds disrupt the thermal gradient and cause mixing of the upper part of the water column.

The validity of this hypothesis was tested by examining the correlation between frequency of strong winds (>30 $\mathrm{km} \mathrm{h}^{-1}$ ) and subsequent lobster yearly landings 5 to $10 \mathrm{yr}$ later for the region of Iles-de-la-Madeleine (Gulf of St. Lawrence, Québec). The rationale behind the choice of Iles-de-la-Madeleine is that this area: (1) has shown relatively high exploitation rates in the past (J.-P Dallaire, Department of Fisheries and Oceans, Maurice-Lamontagne Institute, pers. comm.); (2) presents reliable landing statistics (Hudon et al. 1991); (3) contributes to a large portion of Québec's annual lobster catches (ca $75 \%$; J.-P. Dallaire pers. comm.); and (4) according to its geographical position, is submitted to relatively long fetches $(>85 \mathrm{~km})$ in all directions. The correlations between strong wind frequencies and lobster landings were obtained in 3 steps. First, we calculated daily mean wind velocity (all directions included) for the entire period of larval dispersal and settlement for a $15 \mathrm{yr}$ period (1968 to 1982) for which hourly wind data were available (Environment Canada). For computation purposes the dispersal and settlement periods in Iles-de-la-Madeleine were established after Hudon et al. (1986) from 16 June to 14 September and from 28 July to 7 September respectively. Second, the frequencies of daily mean winds of $0-10,11-20,21-30$ and $>30 \mathrm{~km} \mathrm{~h}^{-1}$ were obtained for the dispersal and settlement periods. Third, lobster landings were correlated to wind frequencies of high velocity $\left(>30 \mathrm{~km} \mathrm{~h}^{-1}\right)$ for 5 to $10 \mathrm{yr}$ lags for both periods. Results clearly show that low adult catches are negatively correlated to frequency of strong wind during dispersal and settlement 8 yr earlier (Table 4 ). This lag time matches closely with those obtained in other studies for the Gulf of St. Lawrence $(9 \mathrm{yr}$, Sutcliffe

Table 4. Homarus americanus. Pearson correlation coefficients ( $r$ ) between lobster landings and high velocity winds during the period of larval dispersal and settlement $(\mathrm{n}=$ sample size). Coefficients were tested on null distribution obtained from a randomization procedure (5000 random permutations for each sample)

\begin{tabular}{|c|c|c|c|c|c|}
\hline \multicolumn{2}{|l|}{ Years } & \multicolumn{2}{|c|}{ Dispersal } & \multicolumn{2}{|c|}{ Settlement } \\
\hline lag & $\mathrm{n}$ & $r$ & $\mathrm{p}$ & I & $\mathrm{p}$ \\
\hline 5 & 15 & -0.28 & 0.20 & -0.37 & 0.11 \\
\hline 6 & 15 & -0.31 & 0.15 & -0.47 & $0.05^{\circ}$ \\
\hline 7 & 15 & -0.24 & 0.21 & -0.34 & 0.12 \\
\hline 8 & 14 & -0.50 & $0.05^{\circ}$ & -0.61 & $0.02 \cdots$ \\
\hline 9 & 13 & -0.47 & 0.08 & -0.53 & $0.05^{\circ}$ \\
\hline 10 & 12 & -0.05 & 0.43 & -0.14 & 0.35 \\
\hline \multicolumn{6}{|c|}{$p=0.05_{i} \cdots p<0.025$} \\
\hline
\end{tabular}

1973; 9 and $10 \mathrm{yr}$, Sheldon et al. 1982; 9 yr, Drinkwater \& Myers 1987; all correlations were obtained using 3 yr running means).

The alternation between stratification and destratification of the water column is determined by the dynamic balance between buoyancy and turbulent kinetic energy inputs. In a system such as the Gulf of St. Lawrence, freshwater supplies and solar heating are the main factors inducing stratification while tidal $\left(\mathrm{M}_{2}\right)$ and wind-induced mixings are responsible for destratification (Pingree \& Griffiths 1980, Bugden et al. 1982). Through exploratory correlation analysis, a positive correlation was observed by Sutcliffe $(1972,1973)$ between the St. Lawrence river discharge and lobster landings in the Gulf. To date, however, the mechanisms underlying that correlation remain speculative (Bugden et al. 1982, Sinclair et al. 1988). The results of the present study suggest that high runoff could increase larval survival by increasing the degree of vertical stratification of the water column. In this new context, the failure of the runoff model (Sheldon et al. 1982) to predict recent Québec lobster landings (see Sinclair et al. 1988) could be attributed to the effect of other factors, such as winds, involved in the process of 
water stratification-destratification. This points out how crucial it is to further our knowledge of the dynamic interaction between larval behaviour and hydrological components to understand the mechanisms determining recruitment of this benthic marine species.

Acknowledgements. We are especially grateful to J.-R. Hamel for his contribution and enthusiasm during experimentation. We also thank R. Rondeau, E. Marcandella, I. Diss and particularly M.F. Pouliot for their help in the laboratory and larval rearing work. F. Cantin helped in building the larval rearing system. This research greatly benefitted from discussions with $\mathrm{L}$. Fortier who kindly provided FORTRAN programs for non-parametric randomization analyses. J. Miron from Environment Canada and E. Lachance from Statistical Division of Fisheries \& Oceans (Québec) provided respectively wind velocity and landing data. E. Holm provided much appreciated linguistic improvements. This research was supparted by the Fisheries Research Division of the MauriceLamontagne Institute and by Fisheries and Oceans and NSERC grants to E.B. B.B. was supported by an NSERC scholarship.

\section{LITERATURE CITED}

Angel. M. V. (1968). The thermocline as an ecological boundary. Sarsia 34: 299-312

Austin, H. M. (1972). Notes on the distribution of phyllosoma of the spiny lobster Panulirus ssp., in the Gulf of Mexico. Proc. natn. Shellfish. Ass. 62: 26-30

Banse, K. (1964). On the vertical distribution of zooplankton in the sea. Progr. Oceanogr 2: 55-125

Boudreau, B., Bourget, E., Simard, Y. (1990). Benthic invertebrate larval response to substrate characteristics at settlement: shelter preferences of the American lobster Homarus americanus. Mar. Biol. 106: 191-198

Boyd, C. M. (1973). Small scale spatial patterns of marine zooplankton examined by an electronic in situ zooplankton detecting device. Neth. J. Sea Res. 7: 103-111

Bruno, M. S., Barnes, S. N., Goldsmith, T. H. (1977). The visual pigment and visual cycle of the lobster, Homarus. J. comp. Physiol. 120: 123-142

Bugden, G. L., Hargrave, B. T., Sinclair, M. M., Tang, C. L. Therriault, J.-C., Yeats, P. A. (1982). Freshwater runoff effects in the marine environment: the Gulf of St. Lawrence example. Can. Tech. Rep. Fish. Aquat. Sci. 1078: $89 \mathrm{p}$.

Caddy. J. F. (1979). The influence of variations in the seasonal temperature regime on survival of larval stages of the American lobster (Homarus americanus) in the southern Gulf of St. Lawrence. Rapp. P.-v, réun. Cons. int. Explor Mer 175: 204-216

Cobb, J. S., Gulbransen, T., Phillips, B. F., Wang, D., Syslo, M. (1983). Behavior and distribution of larval and early juvenile Homarus americanus. Can. J. Fish. Aquat. Sci. 40: $2184-2188$

Cushing, D. H. (1951). The vertical migration of planktonic crustacea. Biol. Rev. 26: 158-192

Dow, R. L. (1969). Cyclic and geographic trends in sea water temperature and abundance of American lobster. Science 164: 1060-1063

Drinkwater, K. F., Myers, R. A. (1987). Testing predictions of marine fish and shellfish landings from environmental variables. Can. J. Fish. Aquat. Sci. 44: 1568-1573
Ennis, G. P. (1975). Behavioral responses to changes in hydrostatic pressure and light during larval development of the lobster Homarus americanus. J. Fish. Res. Bd Can. 32: $271-281$

Ennis, G. P. (1986). Stock definition, recruitment variability, and larval recruitment processes in the American lobster, Homarus americanus: a review. Can. J. Fish. Aquat. Sci. 43: $2072-2084$

Flowers, J. M., Saila, S. B. (1972). An analysis of temperature effects on the inshore lobster fishery. J. Fish. Res. Bd Can. 29: $1221-1225$

Fogarty, M. J. (1988). Time series models of the Maine lobster fishery: the effect of temperature. Can. J. Fish. Aquat. Sci. 45: $1145-1153$

Forward, Jr., R. B. (1976). Light and diurnal vertical migration. photobehavior and photophysiology of plankton. In Smith, K. C. (ed.) Photochemical and photobiological reviews, Vol. I. Plenum Press, New York, p. 157-209

Forward, Jr., R. B. (1988). Diel vertical migration: zooplankton photobiology and behaviour. Oceanogr. mar. Biol. A. Rev. 26: 361-393

Forward Jr., R. B. (1990). Behavioral responses of crustacean larvae to rates of temperature change. Biol. Bull. mar biol. Lab. Woods Hole 178: 195-204

Fragopoulu, N., Lykakis, J. J. (1990). Vertical distribution and nocturnal migration of zooplankton in relation to the development of the seasonal thermocline in Patraikos Gulf. Mar. Biol. 104: 381-387

Gregory, D. N., Verge, E., Languille, P. (1990). Long-term temperature monitoring program: Scotia-Fundy and Gulf of St. Lawrence. Can. Data Rep., Hydrogr. Ocean Sci. 84, $175 \mathrm{p}$.

Hadley, P. B. (1908). The behavior of the larval and adolescent stages of the American lobster (Homarus americanus). J. comp. Neurol. Psychol. 18: 199-301

Hansen, K. V (1951). On the diurnal migration of zooplankton in relation to the discontinuity layer. J. Cons. perm. int. Explor Mer 17: 231-241

Harding, G. C., Pringle, J. D., Vass, W. P., Pearre Jr., S., Smith S. J. (1987). Vertical distribution and daily movements of Iarval lobsters Homarus americanus over Browns Bank, Nova Scotia. Mar. Ecol. Prog. Ser. 41. 29-41

Harding, G. C., Trites, R. W. (1988). Dispersal of Homarus americanus larvae in the Gulf of Maine from Browns Bank. Can. J. Fish. Aquat. Sci, 45: 416-425

Hudon, C., Fradette, P., Legendre, P. (1986). La répartition horizontale et verticale des larves de homard (Homarus americanus) autour des iles de la Madeleine, golfe du Saint-Laurent. Can. J. Fish. Aquat. Sci. 43: 2164-2176

Hudon, C., Legendre, P., Lavoie A., Dubois, J.-M., Vigeant, G. (1991). Effets du climat et de l'hydrographie sur le recrutement du homard américain (Homarus americanus) dans le nord du golfe du Saint-Laurent. Publ. spéc. can. sci. halieut. aquat. 113: 161-177

Hughes, J. T., Shleser, R. A., Tchobanoglous, G. (1974). A. rearing tank for lobster larvae and other aquatic species. Prog. Fish. Cult. 36: 129-132

Kelly, P., Sulkin, S. D., Van Heukelem, W. F. (1982). A dispersal model for larvae of the deep sea red crab Geryon quinquedens based upon behavioral regulation of vertical migration in the hatching stage. Mar. Biol. 72: 35-43

Lauzier, L. (1952). Effect of storms on the water conditions in the Magdalen shallows. J. Fish. Res. Bd Can. 8: 332-339

Legendre, L., Legendre, P. (1984). Ecologie numérique 2. La structure des données écologiques. Masson, Paris

Legendre, P. Fortin, M. -J. (1989). Spatial pattern and ecological analysis. Vegetatio 80: 107-138 
Mackenzie, B. R. (1988). Assessment of temperature effects on interrelationships between stage durations, mortality, and growth in laboratory-reared Homarus americanus Milne Edwards larvae. J. exp. mar. Biol. Ecol. 116: 87-98

Mantel, N. (1967). The detection of disease clustering and a generalized regression approach. Cancer Res. 27 209-220

McConnaughey, R. A., Sulkin, S. D. (1984). Measuring the effects of thermoclines on the vertical migration of larvae of Callinectes sapidus (Brachyura: Portunidae) in the laboratory. Mar. Biol. 81· 139-145

Mcleese, D. W. (1973). Orientation of lobsters (Homarus americanus) to odor. J. Fish. Res. Bd Can. 30: 838-840

Myers, R. A., Drinkwater, K. F. (1989). Offshelf Ekman transport and larval fish survival in the northwest Atlantic. Biol. Oceanogr. 6: 45-64

Oshurkov, V V., Shilin, M. B., Oksov, I. V., Smirnov, B. R. (1982). Seasonal dynamics of meroplankton in Chupa Inlet (White Sea). Sov. J. mar. biol. 8: 1-8

Paffenhöfer, G.-A. (1983). Vertical zooplankton distribution on the northeastern Florida shelf and its relation to temperature and food abundance. J. Plankton Res. 5: 15-33

Perkins, H. C. (1972). Developmental rates at various temperatures of embryos of the northern lobster (Homarus americanus Milne-Edwards). Fish. Bull. U.S. 70: 95-99

Petrie, B. (1990). Monthly means of temperature, salinity and sigma-t for the Gulf of St. Lawrence. Can. Tech. Rep. Hydrogr. Ocean. Sci. 126, 137 p.

Phillips, B. F., Sastry, A. N. (1980). Larval ecology. In: Cobb, J. S., Phillips, B. F. (eds.) The biology and management of lobsters, Vol 2, Ecology and management. Academic Press, New York, p. 11-57

Pillar, S. C., Armstrong, D. A., Hutchings, L. (1989). Vertical migration, dispersal and transport of Euphausia lucens in the southern Benguela current. Mar. Ecol. Prog. Ser 53: $179-190$

Pingree, R. D., Griffiths, D. K. (1980). A numerical model of the $\mathrm{M}_{2}$ tide in the Gulf of St. Lawrence. Oceanol. Acta 3: 221-225

Power, J. H. (1989). Sink or swim: growth dynamics and zooplankton hydromechanics. Am. Nat. 133: 706-721

Rimmer, D. W., Phillips, B. F. (1979). Diurnal migration and vertical distribution of phyllosoma larvae of the western rock lobster Panulirus cygnus. Mar. Biol. 54: 109-124

Scarratt, D. J. (1964). Abundance and distribution of lobster larvae (Homarus americanus) in Northumberland Strait. J. Fish. Res. Bd Can. 21: 661-680

Scarratt, D. J. (1973). Abundance, survival, and vertical and diurnal distribution of lobster larvae in Northumberland Strait, 1962-63, and their relationships with commercial stocks. J. Fish. Res. Bd Can. 30: 1819-1824

Scarratt, D. J., Raines, G. E. (1967). Avoidance of low salinity by newly hatched lobster larvae. J. Fish. Res. Bd Can. 24: 1403-1406

Shanks, A. L. (1986). Vertical migration and cross-shelf dispersal of larval Cancer spp. and Randallia ornata (Crus-

This article was submitted to the editor tacea: Brachyuraj off the coast of southern California. Mar. Biol. 92: 189-199

Sheldon, R. W., Sutcliffe Jr., W. H., Drinkwater, K. (1982). Fish production in multispecies fisheries. In: Mercer, M. C. (ed.) Multispecies approaches to fisheries management advice. Can. Spec. Publ. Fish. Aquat. Sci. 59: 28-34

Simard, Y., Savard, L. (1990). Variability, spatial patterns and scales of similarity in size-frequency distributions of the northern shrimp (Pandalus borealis) and its migrations in the Gulf of St. Lawrence. Can. J. Fish. Aquat. Sci. 47 : $794-804$

Sinclair, M., Anderson, J. T., Chadwick, M., Gagné, J., Mckone, W D., Rice, J. C., Ware, D. (1988). Report from national workshop on recruitment. Can. Tech. Rep. Fish. Aquat. Sci. 1626: $261 \mathrm{p}$

Stasko, A. B., Gordon, D. J. (1983). Distribution and relative abundance of lobster larvae off southwestern Nova Scotia, 1977-1978. Can. Tech. Rep. Fish. Aquat. Sci. 1175: 23 p.

Sulkin, S. D. (1984). Behavioral basis of depth regulation in the larvae of brachuran crabs. Mar Ecol. Prog. Ser 15: $181-205$

Sulkin, S. D., Van Heukelem, W. F., Kelly, P. (1983). Behavioral basis of depth regulation in hatching and postlarval stages of the mud crab Eurypanopeus depressus. Mar Ecol. Prog. Ser 11. 157-164

Sutcliffe, Jr, W. H. (1972). Some relations of land drainage, nutrients, particulate material, and fish catch in two eastern Canadian bays. J. Fish. Res. Bd Can. 29: 357-362

Sutcliffe Jr, W. H. (1973). Correlations between seasonal river discharge and local landings of American lobster (Homarus americanus) and Atlantic halibut (Hippoglossus hippoglossus) in the Gulf of St. Lawrence. J. Fish. Res. Bd Can. 30: 856-859

Templeman, W. (1936). The influence of temperature, salinity, light and food conditions on the survival and growth of the larvae of the lobster (Homarus americanus). J. Biol. Bd Can. 2: $485-497$

Tremblay, M. J., Sinclair, M. (1990). Sea scallop larvae Placopecten magellanicus on Georges Bank: vertical distribution in relation to water column stratification and food. Mar. Ecol. Prog. Ser. 61: 1-15

Turner, J. T., Dagg, M. J. (1983). Vertical distributions of continental shelf zooplankton in stratified and isothermal waters. Biol. Oceanogr. 3: 1-40

Venrick, E. L. (1986). The Smirnov statistic: an incorrect test for vertical distribution patterns. Deep Sea Res. 33: $1275-1277$

Young, C. M., Chia, F.-S. (1987). Abundance and distribution of pelagic larvae as influenced by predation, behavior, and hydrographic factors. In: Giese, A. C., Pearse, J.-S., Pearse, V. B. (eds.) Reproduction of marine invertebrates, Vol. IX, General aspects: seeking unity in diversity. Blackwell Boxford Press, California, p. 385-463

Zar, J. H. (1984). Biostatistical analysis, 2nd edn. PrenticeHall, Englewood Cliffs, New Jersey

Manuscript first received: March 5, 1991

Revised version accepted: June 20, 1991 